\title{
Chemical Study of the Essential Oil of Mutisia Friesiana
}

\author{
C.I. Viturro ${ }^{1}$ and J. De la Fuente ${ }^{2}$ \\ ${ }^{1}$ Fac. de Ingeniería, UNJu - Gorriti 237 (4600) S. S. de Jujuy, Argentina \\ E-mail: degalli@imagine.com.ar \\ ${ }^{2}$ Fac. Cs Ex. UnSa.
}

\begin{abstract}
The composition of essential oil of Mutisia friesiana (Asteracae) was studied. The oil is a complex system in which 127 compounds were identified. The major components are monoterpenes: $\beta$-phellandrene, $(Z)$ - $\beta$-ocimene, $\alpha$ and $\beta$-pinene and sabinene.
\end{abstract}

\section{Introduction}

Coumarins, chromones, aromatic glycosides, sitosterol, lupeol, among others, have been found in Mutisia class species (Asteraceae family). The Mutisia friesiana Cabrera plant is an endemic species of the Argentinean northwest used in the popular medicine and have a pleasing and persistent perfume. It was of interest to do the chemical study of secundary metabolites and determine in a first stage the presence of substance volatile. Studies referred to essential oils (EO) are not found in bibliography for this class.

\section{Experimental}

Wild specimens of $M$. friesiana, identified as Ma (herbarium: Ahumada 7183) y Mb (herbarium: HG1115) were collected in two high places of the Jujuy province: Puna and Quebrada. The EO was extracted from the aerial part by hydrodistillation. It was analyzed by gas chromatography with flame ionization detector and capillary columns DB1, HP5, HP1 y HP-INNOWAX with $\mathrm{H}_{2}$ carrier. The Ma GC/MS was made in a GC-MS Shimadzu QP-500 (LANAIS-EMAR-CONICET) and the Mb analysis in a GC HP 6890 MS HP 5972 A (Agua de los Andes) with He carrier and DB1 y HP5 columns.

\section{Results and Discussion}

The EO yield is similar to other aromatic species $(0,33 \%$ to $0,80 \% \mathrm{v} / \mathrm{w}$ over dry material). One hundred and twenty seven components were identified by comparison of their mass spectra with those reported in literature. Percentage contributions of the different compound families are given in the attached Table. The EO composition of the two different zones of Jujuy is qualitatively similar. Linalool (E)- $\beta$-damascenone, hexanol and (Z)-3-hexenol contribute to the perfume of the essential oil. 
PERCENTAGE DISTRIBUTION OF COMPOUNDS CHEMICAL FAMILIES IN THE COM-

\section{POSITION OF E. O. OF Mutisia friesiana}

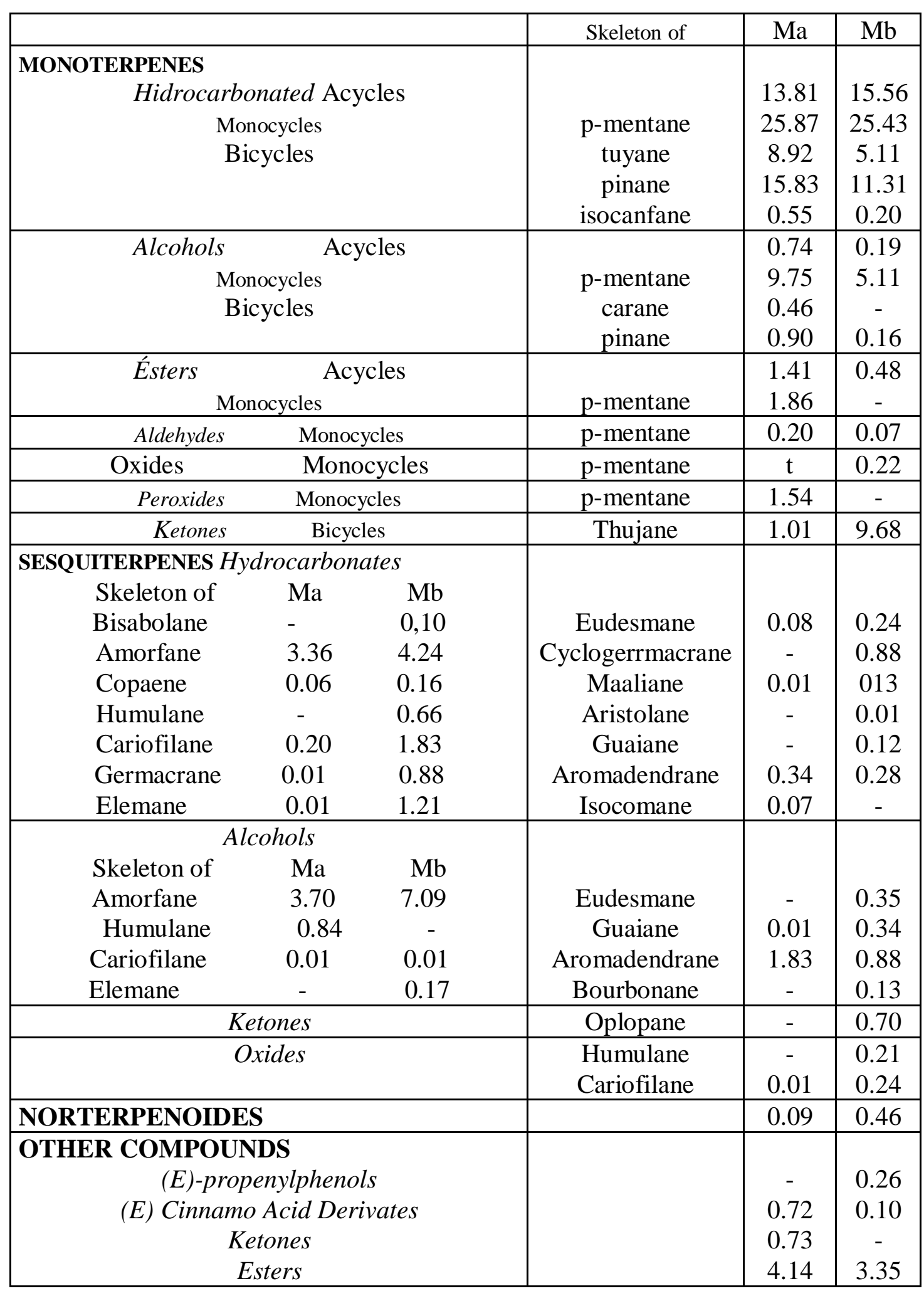


Acknowledgments: To Dr. E. Gros because of his support and the revision of the present work. To the Fac. Ing. (UNJu) for partial financial support.

\section{References and Notes}

1. Daily, A. Planta Medica 1988, 54, 50.

2. Bittner, M. Phytochemistry 1994, 27 (3), 695.

3. Kováts, E. Helv. Chim. Acta 1958, 41, 1915.

4. Davies, N. W. J. Chromatog. 1990, 503, 1.

5. NBS 75K. L. 